* * - ( ) $\rightarrow 40$

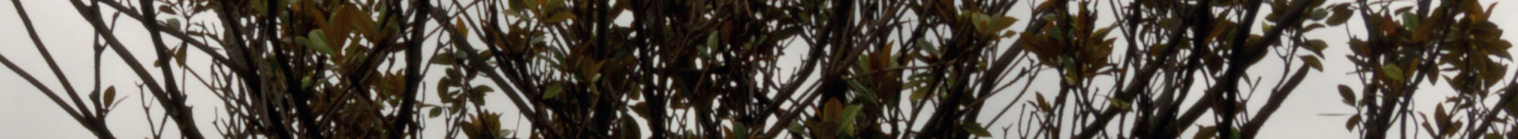
A.

2.t. ...

82

\title{
FRAGMENTOS
}

Espacio de Arte y Memoria 


\section{Fragmentos, espacio de arte y memoria: ¿monumento de memoria histórica o galería comercial de arte contemporáneo?}

\author{
Artículo de investigación \\ Recibido: 10 de abril de 2021 \\ Aprobado: 8 de mayo de 2021 \\ María Mercedes Herrera Buitrago \\ Investigadora independiente \\ mherrerabuitrago@gmail.com

\section{Jorge Peñuela} \\ Universidad Distrital Francisco José de Caldas \\ ipenuela@udistrital.edu.co
}

Herrera, María; Peñuela, Jorge (2022). Fragmentos, espacio de arte y memoria: ¿monumento de memoria histórica o galería comercial de arte contemporáneo? Estudios Artísticos: revista de investigación creadora, 8(12), pp. 48-61.
DOI: https://doi.org/10.14483/25009311.18108

\section{Resumen}

En el presente artículo exponemos los resultados parciales de investigación acerca de espacio, memoria, arte y sociedad igualitaria. Aquí, elaboramos una genealogía del monumento Fragmentos Espacio de Arte y Memoria (FEAM), y exploramos su configuración para evidenciar su origen confuso. Preguntamos, ¿por qué fue designada la artista Doris Salcedo para ejecutar el monumento? ¿Por qué el concepto de justicia restaurativa, del cual debe dar cuenta FEAM, riñe, en nuestro criterio, con el dispositivo de obra de arte contemporáneo? Así, nuestras preguntas van encaminadas a considerar si FEAM contribuye a la reparación simbólica de la sociedad colombiana en tiempos de posconflicto. Además, si bajo su reglamento, es posible construir la memoria histórica necesaria para la transformación del país.

\section{Palabras clave}

Fragmentos Espacio de Arte y Memoria FEAM;

memoria histórica; reparación simbólica; Acuerdo 
Fragmentos, Espacio de Arte y Memoria: A Monument of Historical Memory or a Commercial Gallery of Contemporary Art?

\begin{abstract}
In this article we present the partial results of a research project dealing with space, memory, art and an egalitarian society. We elaborate a genealogy of the monument Fragmentos, Espacio de Arte y Memoria (FEAM) (Fragments, Space of Art and Memory), and we explore its configuration to reveal its confusing origins. We ask, firstly, why was the artist Doris Salcedo appointed to execute the monument? Why is the concept of restorative justice, which FEAM must embody, at odds, in our opinion, with the device of a contemporary work of art? Thus, our questions are aimed at considering whether FEAM contributes to the symbolic reparation of Colombian society in the post-conflict era. In addition, we enquire if, under its rules, it is possible to build the historical memory the country needs for its transformation.
\end{abstract}

\section{Keywords}

Fragmentos, Espacio de Arte y Memoria FEAM; historical memory; symbolic reparation; peace agreement; contemporary art

\section{Fragmentos, Espacio de Arte $y$ Memoria : Monument de mémoire historique ou galerie commerciale d'art contemporain ?}

\section{Résumé}

Dans cet article, nous présentons les résultats partiels d'un projet de recherche sur l'espace, la mémoire, l'art et une société égalitaire. Nous élaborons une généalogie du monument Fragmentos, Espacio de Arte y Memoria (FEAM) (Fragments, espace d'art et de mémoire), et nous explorons sa configuration pour révéler ses origines déroutantes. Nous demandons, tout d'abord, pourquoi l'artiste Doris Salcedo a-t-elle été désignée pour exécuter ce monument? Pourquoi le concept de justice réparatrice, que FEAM doit incarner, est-il en contradiction, à notre avis, avec le dispositif d'une œuvre d'art contemporaine? Ainsi, nos questions visent à examiner si FEAM contribue à la réparation symbolique de la société colombienne dans l'ère post-conflit. En outre, nous nous demandons si, selon ses règles, il est possible de construire la mémoire historique dont le pays a besoin pour sa transformation.

\section{Mots clés}

Fragmentos, Espacio de Arte et Memoria FEAM

; mémoire historique ; réparation symbolique ; accord de paix ; art contemporain

\section{Fragmentos, espaço de arte e memória: monumento de memória histórica ou galeria comercial de arte contemporânea?}

\section{Resumo}

No presente artigo expomos os resultados parciais da investigação acerca de espaço, memória, arte e sociedade igualitária. Aqui, elaboramos uma genealogia do monumento Fragmentos, Espacio de Arte y Memoria (FEAM), e exploramos sua configuração para evidenciar sua origem confusa. Perguntamos, por que foi designada a artista Doris Salcedo para executar o monumento? Por que o conceito de justiça restaurativa, do qual deve dar conta FEAM, está em desacordo, em nossa opinião, com o dispositivo de obra de arte contemporânea? Assim, nossas perguntas vão encaminhadas a considerar se FEAM contribui para a reparação simbólica da sociedade colombiana em tempos de pós-conflito. Além disso, se sob sua regulamentação, é possível construir a memória histórica necessária para a transformação do país.

\section{Palavras-chave}

Fragmentos Espacio de Arte y Memoria FEAM; memória histórica; reparação simbólica; acordo de paz; arte contemporânea

\section{Ñugpa kilkaskata wakachiska chasallata ruraskakunata kawachispa katungapa}

\section{Maillallachiska}

Kai milla kilkaskapi kawachinga munaku paikuna. Tapuchiskata imasami kausanchi iuianchi ruranchi kausanchi. Tukuikuna. Kaipi tiami ruraskata kawachingapa tapuchiku ¿imasamanda sakikaskuna kai warmi Doris Salcedo sui kai katichingapa? ¿imasatak 
kunankama apachiku (FEAM), piñaspa Nukanchipa ruraikunatta? Chimanda tukuikna tapunaku kai suti FEAM, aidachikunchu kawachingapa nukanchpa llakii atun llagta Colomba sutipa tiaskata.

\section{Rimangapa Ministidukuna}

Mailla kilkaska ugpamandata kawachispa; iuiai iuiardur FEAM; iuiarispa ñugpamandata; llakikunata kawai; allilla kaugsangapa parlaikuna; ruraska ima pasariskata

\section{Introducción}

Fragmentos Espacio de Arte y Memoria - en adelante FEAM - es el nombre que Doris Salcedo concibió para el monumento conmemorativo del Acuerdo de Paz firmado entre la guerrilla Fuerzas Armadas Revolucionarias de Colombia (Ejército del pueblo FARC-EP) y el Estado colombiano. Entendemos por conmemorar el constituir memoria con otras y otros en igualdad de condiciones, sin vencedores ni vencidas, sin tutorías estéticas ni ciudadanías subalternas. Para la construcción de FEAM, Salcedo adecuó las ruinas de una casona colonial localizada en el barrio Santa Bárbara, en localidad de La Candelaria en Bogotá. Ubicada a pocas cuadras del centro histórico de la ciudad y del Palacio de Nariño. Según los datos ofrecidos por la prensa, se fundieron 37 toneladas de armamento para obtener 1.300 placas metálicas a manera de baldosas de piso. De esta manera, FEAM está constituido por tres salas de exhibición interconectadas, de las cuales se recuperaron algunos escombros en un lote de 1.200 metros cuadrados. Dicho lote lo había recibido el Instituto Distrital para la Protección de la Niñez y la Juventud (IDIPROM), pero se deterioró de tal forma que amenazó con destruir la casa vecina, es decir, la casa cural de la parroquia Santa Bárbara.

Con FEAM, Salcedo presuntamente atendió las indicaciones estipuladas en el documento Acuerdo final para la terminación del conflicto y la construcción de una paz estable y duradera (Oficina del Alto Comisionado para la Paz, 2016) —en adelante, Acuerdo Final-, en particular, el punto 3.1.1.1. en donde se determinó la dejación de las armas mediante la elaboración de los siguientes conceptos: “Definiciones: Dejación de las armas (DA): Es un procedimiento técnico, trazable y verificable mediante el cual la Organización de Naciones Unidas (ONU) recibe la totalidad del armamento de las FARC-EP para destinarlo a la construcción de monumentos."

Adicionalmente, en el apartado 3.1.7 se estipuló expresamente el destino de estas: "Consiste en un procedimiento técnico, trazable y verificable mediante el cual la ONU recibe la totalidad del armamento de las FARC-EP para destinarlo a la construcción de 3 monumentos, acordados entre el Gobierno Nacional y las FARC-EP" (Cursivas nuestras).

En el Acuerdo final se mencionaron los monumentos acordados. En la fase de extracción del armamento y la disposición final, explicitó:

\footnotetext{
- Extracción del armamento: este procedimiento técnico, a cargo de la ONU, consiste en la salida física del armamento de las Zonas. La ubicación de este armamento será determinada entre el Gobierno Nacional y las FARC-EP con la ONU, el cual será destinado para la construcción de 3 monumentos.
}

\begin{abstract}
- Disposición final del armamento: se entiende como el procedimiento técnico mediante el cual las armas de las FARC-EP se destinan para la construcción de 3 monumentos, así: uno en la sede de las Naciones Unidas, otro en la República de Cuba y otro en territorio colombiano en el lugar que determine la organización política surgida de la transformación de las FARC-EP, en acuerdo con el Gobierno Nacional. (Cursivas nuestras).
\end{abstract}

Por lo tanto, en el Acuerdo Final, el énfasis en la dejación de armas se puso en los procedimientos técnicos para el control del armamento, no en la regulación de la estética de los tres monumentos de carácter artístico. Nótese que la palabra 'acordar', sinónimo de convenir o concertar, contempló la conversación entre dos partes: el Estado colombiano y las FARC. Sin embargo, esa conversación no tuvo lugar, y de manera no justificada, se otorgó a Salcedo la realización del monumento. Además de decisiones trascendentales, como el lugar de emplazamiento, la orientación estética bajo el rótulo de 'arte contemporáneo' y su funcionamiento como concurso de arte. 


\section{Genealogía y origen confuso de FEAM}

Antes de abordar el análisis de la formalidad que frágilmente respalda a FEAM, es importante señalar en qué consiste este estímulo artístico que se convoca periódicamente. Según Daniel Castro, exdirector del Museo Nacional de Colombia, en respuesta al Derecho de petición interpuesto por quienes firmamos este documento, el monumento FEAM:

[...] es el estímulo más importante de arte contemporáneo, ya que como reconocimiento económico permite que artistas desde 10 años de trayectoria puedan participar, viabilización (sic) para la participación de muchos artistas [...] La alianza entre excombatientes y víctimas con artistas no es con el propósito de ponerlos bajo una tutela sino crear una alianza y garantizar el diálogo en Fragmentos, Espacio de Arte y Memoria que está constituido como un espacio de arte por lo cual la temática artística es un pilar de este lugar. De tal manera, el premio está constituido para que víctimas y/o excombatientes puedan trabajar con artistas y viceversa, creando un diálogo entre el arte y la memoria. Lo anterior, se subrayara (sic) ya que se trata de un estímulo de Arte Contemporáneo y con fines artísticos.

Resaltamos la redacción descuidada de la comunicación de Castro como síntoma de una fractura. Que consiste en, por un lado, la memoria urgida de realidad textual, por el otro, el arte ávido de novedades. Así, FEAM es un proyecto con fines artísticos, es decir, comerciales, pues, en la mayoría de las versiones discursivas disponibles en el mercado de bienes suntuarios, el relato de 'arte contemporáneo' es sinónimo de feria de sensibilidades. FEAM no responde a la necesidad social de contar con una escritura incluyente que le dé una imagen al momento crítico en que el Acuerdo Final surge; consiste en un espacio de arte en el cual la grámatica del arte contemporáneo se instituye en el lenguaje oficial que permite la mediación que establece de manera perentoria la justicia restaurativa. Así, lo que importa es la forma, no las personas. Por tanto, llamamos fetichización de la obra, a la absolutización de la forma en detrimento de las personas. Consideramos que la imposición de un lenguaje artístico a la sensibilidad colombiana contradice lo acordado para conmemorar el Acuerdo de Paz, y que FEAM enmascara el lugar de enunciación que rige los estatutos de los cuales habla Daniel Castro.

Asimismo, afirmamos que FEAM es la elaboración personal de Salcedo, no una creación colectiva. Es bien sabido que Salcedo no atendió las recomendaciones que hizo un grupo de expertos, excombatientes de FARC-EP y víctimas del conflicto armado, reunidos en el Coloquio universitario El monumento con las armas fundidas de las FARC-EP ¿Quién/cómo/dónde debería ser/hacer o estar el monumento? Dicho grupo elaboró el documento 29 Recomendaciones, que se entregó a Rodrigo Rivera en su calidad de Alto comisionado para la Paz del Gobierno y a Victoria Sandino, representante de la subcomisión de género y paz de FARC. Entre las 29 recomendaciones para la proyección del monumento, destacamos: el llamado a la dignificación de las víctimas según principios de verdad, justicia, reparación y garantías de no repetición; el papel central de la víctima en el proceso de paz y la participación de todos los actores sociales en la creación y seguimiento del monumento.

En estas recomendaciones se señaló que el monumento debía realizarse "en el lugar donde ocurrieron los hechos, sitios públicos y académicos, tanto de la zona rural como urbana: parques, calles, universidades, colegios y escuelas. También debería contener información relacionada con los hechos victimizantes: nombres, historias, hechos, cifras" (Universidad Externado de Colombia, 2017). Asimismo, el documento recomendó la inclusión y equidad de género, categoría que no hizo visible las violencias contra las comunidades LBGTI, ni esclareció que los debates acerca del género trascienden las relaciones entre mujeres y hombres heterosexuales. Las recomendaciones se encaminaron en la vía de la pedagogía, la inclusión, la virtualidad, el privilegiar los procesos sobre los objetos y hacer del monumento un acto permanente de reparación simbólica. El 20 de septiembre de 2017, momento de la entrega de 29 Recomendaciones a las autoridades pertinentes, aún no se sabía que Salcedo era la elegida. Sobre su designación se tuvo noticia en las siguientes comunicaciones oficiales. 


\section{Primera comunicación, emitida por Presidencia de la República y Ministerio de Cultura: sobre la designación de Salcedo.}

Mediante comunicación oficial del 27 de abril de 2018, el Ministerio de Cultura publicó: “Artista Mario Opazo hará el monumento a la paz que se instalará en la sede de la ONU en Nueva York, anunció el presidente Santos" (Ministerio de Cultura, 2018). En esta publicación se comunicó que el artista chileno había ganado el concurso abierto por el Ministerio de Cultura para hacer el monumento ubicado en la sede de las Naciones Unidas. El comunicado agregó: “[...] mientras tanto, la colombiana Doris Salcedo elaborará la obra de arte ${ }^{1}$ que se ubicará en Bogotá y está por definirse lo referente al monumento que se erigirá en La Habana, donde se llevaron a cabo las negociaciones" (Ministerio de Cultura, 2018). Mediante esta comunicación, el presidente Juan Manuel Santos afirmó que el monumento ubicado en Colombia "estará a cargo de la talentosa artista colombiana Doris Salcedo. Su obra se llamará 'Fragmentos' y se espera que esté lista en agosto de este año" (Ministerio de Cultura, 2018). Según el comunicado, la ministra Mariana Garcés:

Agregó que para ello el Ministerio abrió una convocatoria que cerró el pasado 19 de abril y se estableció un jurado conformado por la artista visual Clemencia Echeverri, el curador y crítico de arte José Ignacio Roca y el director de cine, escritor y poeta Lisandro Duque. La convocatoria estuvo abierta a artistas colombianos o extranieros que residan en el país al menos en los últimos cinco años. En total se recibieron 28 proyectos provenientes de diferentes regiones del país (Ministerio de Cultura, 2018).

A este respecto señalamos que la ciudadanía no tuvo información acerca de las razones que llevaron a la ministra a postular como jurados a las personas mencionadas. Es conocida la trayectoria de Duque como director de cine, aunque desconocemos qué pudo aportar a la evaluación de los proyectos presentados. También, Sabemos que las trayectorias de Roca y Echeverri se han destacado por la divulgación en Colombia de las gramáticas de la estética que anima el arte que se

1 Cursivas nuestras. produce en la ciudad de Londres. Evidenciamos en su hoja de vida una solidaridad estética que es importante para la proyeccción internacional del mercado del arte colombiano. Sin embargo, el momumento conmemorativo con el cual se simboliza el comienzo del final de conflicto armado en Colombia, no tiene como propósito la promoción comercial de las figuras más publicitadas del arte colombiano. Más bien, su propósito es atender las necesidades de quienes fueron ofendidas de múltiples y diversas maneras, y sobre este particular, los jurados no tuvieron competencia. Por otro lado, Bogotá y Londres están muy lejos una de la otra si se las compara por su desarrollo económico, su producción social y su estabilidad política.

Hacemos notar que, la complejidad de la situación en la que emergió la necesidad de producir una imagen como símbolo del final de la guerra, ameritaba la participación efectiva de los actores políticos y sociales involucrados. De la misma manera, decidir acerca de la estética más adecuada para emprender la tarea de la reconciliación simbólica como punto de partida de la reconciliación, debió ser un trabajo colectivo, diverso e incluyente. No se trataba solo de hacer algunas consultas a un comité de expertos en arte contemporáneo, tampoco de elegir entre realismo socialista o realismo neoliberal. En resumen, la importancia individual de cada jurado no justificó su designación para seleccionar la propuesta ganadora de la convocatoria. Es evidente que desde el principio las cartas estaban marcadas por una ideología estética. No hubo participación efectiva como lo exige la justicia restaurativa. Mucho menos consultas amplias acerca de cuál debería ser el lenguaje que sirviera de mediador entre las víctimas y los ofensores. En este sentido, compartimos la preocupación de Mario Opazo, quien fue entrevistado por Claudia Palacios en el programa Mejor Hablemos. En este espacio, el artista se quejó con discreción acerca del manejo cerrado que se le dio a una actividad de carácter restaurativo, no solo público, centrada en términos de la atención que requieren las víctimas, más allá de la justicia convencional.

Así, la inquietud que le manifestó Opazo a Palacios evidenció el sesgo sectario e ideológico con el cual se administró y se sigue administrando FEAM. La periodista cuestionó el por qué se le entregó 
a un artista chileno un encargo de tanta relevancia simbólica para la sociedad colombiana, pero sabemos que por los lenguajes que trabajan tanto Salcedo como Opazo es más colombiano este último. Además, la periodista acertó cuando se preguntó por qué ha tenido mayor despliegue mediático la propuesta de Salcedo que la obra de Opazo.

Volvamos al comunicado del Ministerio de Cultura. Allí se agregaron datos relevantes de la trayectoria y la obra artística de Salcedo. Sin embargo, se omitieron referencias al trabajo de la artista con comunidades específicas. La ministra Garcés justificó la designación de Salcedo apelando a una tradición artística que se destaca por la preocupación legítima por la circulación comercial de los objetos de arte; y no tanto por el cuidado real de las personas de las cuales se ocupa el Acuerdo final. Esta circulación comercial se muestra menos inquieta por la desigualdad ciudadana, y más por el cultivo de lenguajes artísticos que no logran trascender el entendimiento de las élites estéticas y sociales de Colombia, afines todas ellas a la estética anglosajona. Como dijo Opazo en el programa Mejor Hablemos, el 'capital' social de Salcedo y de otros artistas contemporáneos como él mismo, se constituye en garantía estética para la producción de obras. Notemos que el 'capital' al que alude Opazo es el que determina lo social. Luego, no se trataba solo de contar con competencias formales para producir obras de arte contemporáneo para el mercado. Consideramos que el mismo concepto de 'obra' no es relevante para comprender el monumento que pretendía conmemorar el fin de la guerra con las FARC-EP ${ }^{2}$ porque en sobradas ocasiones, hemos presenciado cómo la religión de la 'obra' de arte contemporáneo y sus rituales, invisibilizan el dolor de las víctimas.

Ahora bien, con esta primera comunicación, la Presidencia de la República y el Ministerio de Cultura legitimaron la elaboración de dos de los tres monumentos contenidos en el Acuerdo de Paz. Nótese también que este comunicado dio por hecho que el monumento de Salcedo sería en Bogotá. Esto desatendió lo expresado en el Acuerdo final: " $y$ otro en territorio colombiano en

\footnotetext{
2 Para un estudio del concepto de "obra de arte" en la
} contemporaneidad, cf. Agamben (2019). el lugar que determine la organización política surgida de la transformación de las FARC-EP, en acuerdo con el Gobierno Nacional" (Ministerio de Cultura, 2018). Así visto, consideramos que resultó más efectiva la poética de Opazo para el monumento de la ONU frente a FEAM. Pues, en esta última el dolor de las víctimas fue reducido a concepto, a discurso, a explicaciones banales, todas ellas impropias para favorecer un duelo no mediático.

De esta supuesta primera convocatoria hubo elementos que se escaparon a nuestra comprensión y conocimiento. Si atendemos al testimonio de Opazo, en dicha convocatoria no participó Salcedo, pues, cuando Opazo decidió participar, Salcedo ya estaba ejecutando los recursos asignados:

Palacios: Los tres artistas elegidos para la obra, para las tres esculturas, ¿alguna vez se hablaron? Es decir, usted con Doris Salcedo, no sé quién es la persona elegida para la escultura de Cuba, como para pensar si esto de alguna manera pudiera ser, no sé si esta es la palabra correcta, un tríptico, pues, como una cosa con cierta continuidad o relación entre lo uno y lo otro

Opazo: No y fijate que yo siempre tuve... es decir, cuando conocí la convocatoria, yo no sabía que ya se estaba avanzando en otro monumento, que era el de Doris Salcedo. Yo recibí la convocatoria, la estudié, me interesó, precisamente porque he estado muy relacionado con la... con esos estados de realidad. Como te estaba contando, y hay algo que me preocupó, y es por qué no se aprovechó ese momento precisamente para dos cosas: una, abrir más allá del ámbito de las artes las convocatorias, si se trataba de convocatorias, porque pienso que el tema de la conmemoración no es un asunto exclusivo del arte, aunque el arte en su sentido de lo público trae consigo y es inherente la memoria y la conmemoración. Eh... pero una preocupación fue por qué no abrirlo a otras disciplinas, a otros grupos humanos, y por otro lado, por qué justo en ese momento que podíamos dar gala de participación de una suerte de relación abierta, se debía caer como en unas estrategias tan mediadas por las industrias culturales como tomar decisiones como asignarle de manera directa a un artista, luego inventarnos una convocatoria de un modo para el otro, y luego otro tipo de convocatoria para el otro.

Palacios: Sí, hacerlo muy encerrado en el ámbito del arte y no más abierto al resto de la realidad colombiana. Bueno, 
entre otras cosas habiendo por ejemplo tantas víctimas de la violencia que han participado en procesos de sanación que terminan siendo procesos artísticos (Mejor hablemos, 2019).

Así pues, tanto Palacios como Opazo se percataron del sesgo ideológico de FEAM. Una y otro notaron la importancia de simbolizar la diversidad artística, cultural y estética de Colombia. Ahora bien, dado que en el Acuerdo de Paz la realización de los monumentos no tuvo relación con la producción artística nacional sino con la Dejación de Armas (DA), es importante resaltar lo que narró Opazo acerca de los materiales con los que debió trabajar. Cuando este artista quiso recolectar el material de los fusiles ya todo había sido utilizado por Salcedo, entonces, a él solo le quedaron las municiones. Así lo informó El Espectador:

Al trasladarse hasta el municipio de Sogamoso (Boyacá), donde queda la empresa de fabricación de armas del Estado, Industria Militar Colombiana (Indumil), le dijeron que las armas que entregaron las Farc ya se habían acabado, que su colega, Doris Salcedo, las había usado para construir "Fragmentos" y que solo quedaban toneladas de munición (como balas de armas de pequeño calibre) para construir su obra. 'Al principio me generó una enorme preocupación, pero acepté porque había considerado el bronce para la construcción de mi obra, no solo el hierro. Entonces hubo una fortuna de azar y terminé utilizando siete toneladas de munición de las 30 que estaban ahí. Indumil no se encargó del proceso de fundición de ese material y Opazo prefería trabajar con una fundidora con la que ya venía adelantando el proceso (Arboleda Zárate, 2019, cursivas nuestras).

Ahora bien, al anuncio oficial del presidente Santos le sucedieron varios actos administrativos que sellaron el destino de FEAM. Dichos actos no fueron socializados:

\section{a) El 31 de julio de 2018, mediante la Resolución 2655 de 2018 expedida por el Ministerio de Cultura y titulada "Por la cual se define la administración del Monumentos "Fragmentos", el Ministerio decidió:}

En el artículo primero: se le asigna al Museo Nacional de Colombia la gestión administrativa, atención al público, protección y conservación de Fragmentos; en el artículo segundo se ordena la creación del Comité de Actividades Artísticas conformado por:

Doris Salcedo, por ser la creadora del monumento;

El Director del Museo Nacional;

El director de Artes del Ministerio de Cultura;

El presidente de Cámara de Comercio de Bogotá;

La Secretaria Distrital de Cultura, Recreación y Deporte de Bogotá;

La Directora de Patrimonio Cultural de Universidad

Nacional de Colombia.

Aunque los funcionarios que dirigen las instituciones designadas para la administración de FEAM son transitorios, no pasa desapercibido el sesgo estético de los agentes culturales que determinaron el cambio de la función de este espacio. Es decir, dejar de ser un momumento de conmemoración y ponerse al servicio del arte contemporáneo, per se. Por lo anterior, cabe preguntarse: ¿por qué el presidente de la Cámara de Comercio de Bogotá hace parte del Comité de Actividades Artísticas de FEAM? ¿Por qué no hay ningún representante o delegado del partido FARC? ¿Por qué no hay ningún representante o delegado de las víctimas del conflicto armado colombiano? ¿No es acaso a ellos a los que se debe este monumento de la terminación del conflicto y quienes deben ocupar un lugar central en el marco de la Justicia Transicional?

Continuando con el acto administrativo expresado mediante la resolución citada, pasamos a analizar las funciones del Comité que gobierna FEAM. En el artículo tercero se establecieron las funciones del Comité: "definir la programación complementaria de la obra artística, la gestión de recursos complementarios y apoyos para el desarrollo, promoción, defensa y divulgación de las actividades culturales y artísticas para Fragmentos" (Resolución 2655, 2018).

Según información obtenida mediante el Derecho de petición interpuesto por quienes firmamos este documento, dicho Comité de Actividades Artísticas tiene autonomía técnica y administrativa y la Dirección del Museo Nacional dirige a su vez FEAM. Sin embargo, en el documento se menciona: "le informamos que mediante acta de Comité Artístico con fecha del 6 de febrero de 2019. (Sic). Este comité designó a Kristina Mclean, mediante un contrato de prestación de servicios 
como directora de Fragmentos, Espacio de Arte y Memoria". Sabemos que Mclean es representante de la feria de arte Frieze en América Latina, y autora de la guía turística Soy Bogotá. También, es antigua miembro de la banca y no es experta en temas de conflicto armado, acuerdos de paz o transición de la sociedad en camino a conseguir la paz.

\section{Segunda comunicación, emitida por la artista Doris Salcedo: sobre generalidades de Fragmentos y cómo le ofrecieron un lote.}

Por otra parte, el 31 de julio de 2018, Salcedo realizó el discurso central del acto de pre-inauguración del monumento Fragmentos. La artista habló en primera persona acerca de lo que una y otra vez afirmó ser un trabajo colectivo en medio de un evento cerrado, jerárquico y excluyente. De dicho evento nos llamó la atención el juego de su constelación conceptual: vacío y ausencia. También el olvido de palabras claves para comprender los ejercicios con los cuales su nombre es un monumento del arte contemporáneo. Las palabras ausentes fueron: poder, democracia, mercado, mercancía y neoliberalismo. Nos preguntamos, icómo un discurso que no incorpora críticamente estos conceptos puede ser considerado contra-cultural y sustentar la idea de contra-monumento? O si, por el contrario, ¿este discurso encubrió su soberbia estética y social como ejercicio de poder institucional? Según Arcadia, Salcedo expresó:

Preferí no construir un monumento porque, como su nombre lo indica, el monumento es monumental; jerarquiza y presenta una visión triunfalista del pasado bélico de una nación. Su principal función es someternos o empequeñecernos como individuos frente a una versión grandiosa y totalitaria de la historia (Arcadia, 2018).

Paradójicamente, FEAM ostenta una estética triunfalista que empequeñece a todas aquellas personas que sobreviven en territorios dejados a su suerte por parte del Estado colombiano. Salcedo presentó su contra-monumento como un museo de arte contemporáneo y memoria para conmemorar la deposición de las armas: "Hoy nos encontramos en este contra monumento titulado
Fragmentos, que será un museo de arte contemporáneo y memoria, cuyo piso o fundamento está literalmente conformado por las armas depuestas por la antigua guerrilla de las Farc" (Arcadia, 2018). Pero FEAM solo acoge aquello que habla en la lengua del arte contemporáneo y que, sin convencer, pretende emular los diálogos de La Habana. Tiene algo de provocador: convoca 'memorias antagónicas' rechazando las estéticas con las cuales el arte contemporáneo es incompatible. Así, FEAM, como un lugar de vacío y ausencia, se aparta de las personas que son de interés en el Acuerdo Final. Como obra monumental sobre el vacío y la ausencia que pregona el arte contemporáneo, no sirve como mediadora. No se trata de compensar el horror de la guerra con la belleza silenciosa del arte contemporáneo. Pero tampoco con vacíos y ausencias sublimes, tal como Salcedo lo expresa:

Fragmentos presenta únicamente el vacío y la ausencia, porque es precisamente a través de estos elementos que puedo establecer el carácter absolutamente irredimible de la guerra. El arte no puede compensar con belleza el horror causado por la guerra, y por esta razón Fragmentos no intenta otorgar una forma estética a la pérdida, el daño o la muerte violenta (Arcadia, 2018).

De esta manera, FEAM rinde culto a la forma, a lo sublime burgués. Con respecto a este último apartado, consideramos que FEAM obliga a las mujeres violentadas a que hablen en un lenguaje que no es el suyo. El martilleo de estas mujeres sobre láminas de metal se puede leer como una performance artística, pero nada más. Las mujeres no logran elaborar un signo propio que les ayude a comprender de otra manera la violencia padecida. A ellas se les exige modelar los signos de la artista contemporánea. La participación de las víctimas está supeditada a la invitación y la posterior dirección escenográfica por parte de la artista. Mientras Salcedo está convencida de que la participación en la elaboración de una 'obra de arte' sí redimirá a las víctimas. La concesión no repara. Al contrario, instrumentaliza ahondando la condición de exclusión en la que se enmarca a las participantes. Las víctimas son escogidas según el delito que sufrieron en sus cuerpos. Son víctimas sin agencia, sin protagonismo real, una vez más sometidas, esta vez por la estética de Estado. 
De la guerra no queda experiencia, solo trauma. Consideramos que FEAM confunde trauma con experiencia. Salir del trauma es posible por medio del habla tejida en común sobre lo común. Pero a las mujeres convocadas no se les dejó hablar. Fueron despojadas una vez más de lo común sensible a ellas. Para completar el discurso, Salcedo proyectó el lugar de exhibición de obras de arte a 53 años: "Fragmentos, este lugar de memoria, tiene como misión producir y exhibir durante un periodo equivalente a la duración del conflicto diferentes obras de arte que reelaboren la memoria de la guerra" (Arcadia, 2018).

Ahora bien, ante la pregunta de cómo le fue encomendada la realización del monumento en Colombia, llama la atención el testimonio de Salcedo:

Fragmentos fue hecho para ofrecerle a la gente un lugar donde pensar. Es solamente eso: un lugar desde donde pensar en nuestra realidad, lo que nos ocurrió, por qué nos ocurrió. Y ese lugar no existía. Por eso decidí que tenía que ser un edificio. Me ofrecieron entonces unos espacios en el CAN (Centro Administrativo Nacional) que no me interesaron para nada porque yo pensaba que, en el caso de Fragmentos, estar al lado del centro de gobierno era importantísimo. La memoria no es marginal, tiene que estar inscrita en el centro mismo de la vida política de este país. Entonces el distrito donó ese lote en el que se construyó finalmente y, junto al arquitecto Carlos Granada, desarrollamos el proyecto (Malagón Llano, 2019).

Según Salcedo, antes de FEAM no era posible pensar en Colombia. La artista está convencida de que solo en el espacio inventado por ella es posible pensar. Desconoce, o por lo menos demerita, que pensar es posible de mil y una maneras. A su pesar, ignora la diversidad de pensar.

\section{Tercera comunicación, emitida por la administración de FEAM: sobre convocatorias y carácter de los premios y quién adjudicó a Salcedo la realización del monumento.}

a) El 6 de agosto de 2018, mediante la resolución No. 2736 expedida por el Ministerio de Cultura, se dió apertura a la convocatoria para comisionar dos intervenciones artísticas en el espacio Fragmentos. En esta resolución, se condicionó una eventual participación de las víctimas y excombatientes en FEAM porque podrían hacer parte de este espacio, siempre y cuando se asociaran con un artista que cumpliera los requisitos generales de la convocatoria. Así, lo que importó fue la forma absoluta, no las personas. A las víctimas y a los excombatientes se les obligó a rendir culto a la forma, al fetiche de la obra de arte contemporáneo.

b) Según la resolución 3765 del 26 de octubre de 2018 se designaron jurados para la convocatoria a María Belén Sáez de Ibarra, Doris Salcedo y Angélica González.

c) El 6 de noviembre de 2018, según el Acta de deliberación de la convocatoria, Salcedo, siendo jurado, premió a Clemencia Echeverri, quien a su vez había sido jurado de la convocatoria donde salió elegido Opazo. Así puede notarse el tráfico de influencias que operó en FEAM. Los ganadores de la primera convocatoria pública fueron Clemencia Echeverri y Felipe Arturo, lo cual es síntoma de la forma como operan los programas de estímulos artísticos del Estado colombiano, de manera cerrada, sectaria.

d) El 16 de noviembre de 2018, mediante la Resolución 3966. "Por la cual se acoge el acta del veredicto de los jurados para la Convocatoria Fragmentos, se ordena el desembolso de los estímulos a favor de los ganadores".

A estos actos administrativos habría que agregar la información brindada por el Museo Nacional de Colombia en respuesta al Derecho de petición interpuesto por quienes firmamos este documento. En este instrumento solicitamos información sobre la designación de Salcedo y nos contestaron lo siguiente:

En el marco de lo establecido en el punto 3.1.7 del Acuerdo Final para la Terminación del Conflicto, la artista Doris Salcedo presentó el proyecto "Fragmentos" [...] De acuerdo a la visión de la artista, el monumento tiene como visión producir y exhibir obras de arte contemporáneo que reflexionen y reelaboren durante un periodo de 53 años, los hechos violentos que marcaron nuestro pasado reciente. [...] El proyecto de monumento "Fragmentos" fue presentado ante la Comisión de Seguimiento, Impulso y 
Verificación a la Implementación del Acuerdo Final- CSIVI y el 15 de febrero de 2018, mediante comunicación suscrita por la secretaría técnica de dicha instancia, se solicita al Ministerio de Cultura dar curso al monumento. El proyecto artístico fue presentado y autorizado en la primera sesión del Consejo Nacional de Patrimonio celebrado el 8 de marzo de 2018. También fue presentado por la artista ante la Comisión de Seguimiento, Impulso y Verificación a la Implementación del Acuerdo Final.

Según esta información, la asignación de Salcedo para ejecutar el monumento no pasó por convocatoria pública, al contrario, fue una propuesta presentada por la artista a la Comisión de Seguimiento, Impulso y Verificación el 15 de febrero de 2018, y autorizada por el Consejo Nacional de Patrimonio el 8 de marzo de 2018.

\section{Cuarta comunicación, emitida por la directora y la curadora de FEAM: sobre FEAM como plataforma de arte contemporáneo.}

Tanto la directora Kristina McLean como la curadora asociada Taiyana Pimentel, fueron presentadas a nivel internacional en la publicación Agenda Vogue en el artículo Conflicto y creación. Allí, exaltaron a FEAM por ser el espacio de arte contemporáneo más visitado en Bogotá. También le calificaron así: "un contramonumento-vivo que busca un diálogo entre la obra de Doris Salcedo y las nuevas producciones de CREADORES tomando en cuenta paralelismos entre la situación de Colombia y otros lugares del mundo" (González, 2019). Según la publicación, la finalidad de FEAM es "ser uno de los espacios más relevantes para el arte contemporáneo en Latinoamérica a través de la programación y exhibiciones" (González, 2019).

Sobre este particular, vemos con preocupación cómo los medios de comunicación han silenciado cualquier pregunta o voz crítica. La nota laudatoria del periodista Daniel Carreño León es ejemplo de ello:

Que no quepa duda alguna sobre el hecho de que la creación de Doris Salcedo es una importantísima obra de arte contemporáneo. El simbolismo del que están cargados tanto la producción final como el acto colaborativo que fue parte de su desarrollo es impactante y poderoso. [...] La intención de la maestra Salcedo de que, por los próximos cincuenta años, este espacio neutro y vacío sirva como galería para exponer la mirada de otros artistas afectados por el conflicto que lo complementen -independiente de en qué lado estuviesen-es, en mi opinión, la invitación más contundente a la reconciliación (Carreño León, 2019).

\section{Justicia restaurativa vs. Obra de arte contemporáneo}

Asumiendo que los monumentos del Acuerdo de Paz quedaron enmarcados dentro de la literatura que establece la Justicia Restaurativa (JR), consideramos que para la comprensión de dicho modelo y de su relación con el arte y la cultura es necesario atender a lo expresado por la Doctora Yolanda Sierra León. Quien es abogada y restauradora de obras de arte y patrimonio cultural; PhD en Sociología Jurídica de la Universidad Externado de Colombia; docente investigadora y coordinadora de la línea de investigación en Derechos culturales: Derecho, arte y cultura. De sus aportes a la discusión citamos el siguiente apartado:

La justicia restaurativa, es un tipo de justicia relacional alternativa al sistema de justicia penal tradicional, pero sin resultar incompatible con el mismo, porque sus diversas medidas o los diferentes programas de implementación, son flexibles en su adaptación e incluso pueden desarrollarse paralelamente. Así, la justicia restaurativa se caracteriza principalmente por la participación y la dinamia (sic) interactiva entre las partes involucradas en el proceso restaurativo, estos son, víctima o víctimas, ofensor u ofensores, autoridades estatales (si se quiere y cuando hay participación por acción u omisión del Estado) y el conglomera (sic) social, en la solución de un determinado conflicto que resulta latente o que tiene una causa anterior en el tiempo, pero cuyas consecuencias siguen siendo manifiestas en el presente, por lo general, con la ayuda de un mediador (Sierra León, 2017, p. 17).

Con base en este concepto, comprendemos que la justicia restaurativa es relacional, y que en la realización de las acciones que se requieren para consolidar la paz, es necesario un 'mediador'. Sobre este último, no se dice que deba ser un juez o un conjunto de jueces, que es la figura emblemática de la justicia penal ordinaria. Por el contrario, 
podemos inferir legítimamente que una artista puede jugar un papel muy importante entre las partes involucradas en un conflicto tan complejo como el colombiano. Con la condición de que esta artista no asuma un rol protagónico, ni el papel de juez. Mucho menos que haga de la memoria violentada una historia de ficción narrada con la tutela gramatical del arte contemporáneo. Por tanto, esta figura de mediador riñe con el culto a la personalidad que caracteriza al artista contemporáneo y su gramática visual. Así, bajo esta perspectiva, la acción de toda mediadora debe caracterizarse por la discreción para que las personas ofendidas y los ofensores puedan en efecto hablar y asumir responsabilidades. Es por esto por lo que, parte del trabajo relacional y mediado por figuras que no son jueces togados, es fundamental para la Justicia Transicional.

Podemos complementar el planteamiento de la doctora Sierra con la exposición de la doctora Gina Paola Rodríguez, en donde se habla sobre la importancia de animar el diálogo entre ofendidos y ofensores, e identificar las necesidades de quienes le reclaman al Estado la implementación de una justicia integral. Según Rodríguez, el enfoque restaurativo permite mirar en primer lugar a las víctimas, no tanto los intereses ideológicos del Estado, el cual dentro del sistema penal se presenta como víctima. El desplazamiento de las formas jurídicas hacia las personas caracteriza a la justicia restaurativa. De ahí la controversia jurídica, pues, con la idea de que las personas son las que cuentan y no las formas, configura otra manera de relacionarnos. Como ya lo mencionamos, paradójicamente, en FEAM lo que cuenta son las formas y el culto a la artista que identifican al arte contemporáneo. FEAM no ha comprendido la justicia restaurativa. Sobre este modelo de justicia, Rodríguez plantea que:

[...] el enfoque restaurativo parte de la idea de que el delito atenta contra las personas y sus relaciones y que, en esta medida, la acción de la justicia debe orientarse a la identificación de sus necesidades y obligaciones animando el diálogo y el mutuo acuerdo, dando a víctimas y ofensores un rol central, y definiendo las penas de estos últimos en función de su capacidad para asumir responsabilidades y reparar a sus víctimas. Lo que subyace a los planteamientos de la JR es, por un lado, una crítica a las nociones de delito y delincuente sostenidas por la Justicia Penal, y por otro, un replanteamiento del papel que ha de ocupar el castigo en el conjunto de las relaciones sociales. Para los defensores de la JR, el delito es un daño en contra de un individuo particular y la comunidad en la que habita, a diferencia de la justicia penal, que plantea que el delito atenta contra una norma jurídica, siendo el Estado la principal víctima (Rodríguez, 2011, p. 56).

La justicia restaurativa (JR) se orienta teniendo en cuenta la actitud de quienes han ofendido a las víctimas, atendiendo a su "capacidad para asumir responsabilidades" (Rodríguez, 2011), de confesar los delitos para repararlos. Lo que importa no son las grandes penas que exige el Estado para unos delitos. Lo relevante es la reparación efectiva de las víctimas. La mayoría de las veces, las controversias formales propias de la justicia penal ordinaria llevan a la impunidad. Por esto mismo, esta no es garantía de justicia restaurativa. Siguiendo a Rodríguez:

En este sentido, la JR implica un virage (sic) en la concepción mantenida por el derecho penal con respecto al papel de la ofensa y el castigo, al desplazar la atención del acto criminal y el delincuente hacia la atención de la víctima y el daño que le fue ocasionado. Partiendo del supuesto de que el castigo retributivo es insuficiente para la compensación de las víctimas y el logro de la convivencia social, este nuevo paradigma enfatiza en el reconocimiento del sufrimiento ocasionado a las víctimas, su reparación y restauración, antes que en el castigo del responsable, a quien a su vez le corresponde el derecho a ser desestigmatizado y reincorporado a la comunidad para restablecer sus vínculos sociales. Ocupando ahora un lugar central, el ofensor debe adquirir conciencia de los daños que ha ocasionado, asumir un papel activo en la reparación de la víctima y prometer a la comunidad la no reincidencia" (Rodríguez, 2011, p. 56).

Allí, tanto las víctimas como los ofensores asumen un papel protagónico. La justicia restaurativa no solo se centra en las víctimas, también les garantiza a los ofensores que tendrán nuevamente un lugar dentro del pacto simbólico. Lejos de los reflectores del espectáculo, es en torno a los diálogos entre los integrantes del conflicto, auspiciados por la mediadora, que se deben dar los procesos de restauración. Es importante considerar aquí una idea de Zizek con respecto a la condición de víctima. ¿A quién beneficia? Según Zizek (2018), [...] "da mucha más satisfacción sacrificarse por la pobre víctima que dejar que el otro pierda la 
condición de víctima, y quizá incluso tenga más éxito que nosotros". De esta manera, desde la perspectiva que nos proporciona el arte contemporáneo, podemos decir que hay una satisfacción estética y económica cuando aparentemente se les da la voz a las víctimas. Es un riesgo que las víctimas.

Para comprender a fondo la importancia de las artes dentro de la reconstrucción del pacto simbólico con el cual está comprometida la sociedad colombiana, señalamos brevemente los tres objetivos para un programa de Justicia Restaurativa propuestos por Sierra León: “Centrar la atención del proceso en las necesidades, inquietudes y expectativas de las víctimas (...) Buscar la paz, mediante la reconstrucción de los lazos sociales en sus esferas políticas, económicas, sociales, culturales (...) Sembrar en el ofensor el compromiso de no reincidencia" (Sierra León, 2017, p.19).

\section{Conclusiones}

Las artes hacen posible la transformación de la sensibilidad del ser habituado a la injusticia. Si las artes asumen con coraje su responsabilidad social, deben comprender a cabalidad qué es la justicia restaurativa. También, hablarse entre sí, hacer un frente común para propiciar la participación abierta de las artistas en la recuperación de la memoria personal de las víctimas y de la confianza social en el nuevo pacto simbólico. Asimismo, urge salir del estilo de los vacíos y las ausencias que promueve la versión de estado del arte contemporáneo. Esto, pues por sí misma esta estética absolutizada no es garantía de reparación simbólica ni de la necesaria construcción de la memoria histórica que requiere la realidad por venir. La reparación simbólica va en sentido contrario a esta modalidad de arte contemporáneo. Se centra en los relatos de las personas violentadas, propicia la irrupción de las lenguas ignoradas por el régimen de la representación oficial. Así, en este tipo de proyectos, es importante transitar del ego estético con que se modela el artista contemporáneo al sujeto social con principios éticos.

Estimamos que bajo las disposiciones actuales FEAM como premio de arte contemporáneo justificado en una presunta reivindicación de la memoria de miles de vencidas y vencidos con crueldad e ignominia, se ha constituido es un espacio de competencia artística y rivalidad estética. Por esto, está lejos de ser un lugar de solidaridad social y reivindicación de aquellas expresiones políticas, éticas y estéticas que han sido marginalizas por el Estado.

Proponemos que FEAM contribuya a la reparación simbólica y a la construcción de memoria histórica atendiendo prioritariamente las obligaciones jurídicas de los modelos alternativos de justicia. No solo por ser un punto de Acuerdo de Paz, sino porque actualmente representa un oneroso gasto anual a cargo del erario para sostener el egoísmo propio de una galería de arte contemporáneo. De lo contrario, FEAM no hará nada distinto de auspiciar el modelo económico que sostiene al régimen estético constituido por la 'obra de arte contemporáneo'. El secreto de esta plusvalía de guerra se revela una vez nos percatamos de que la gramática estética que despliegan los y las artistas convocadas, está diseñada para expoliar la memoria, para olvidar la existencia real de las sobrevivientes, para sumar ausencias, y no para recordar ni inventar la sociedad por la cual han muerto millones de mujeres y hombres.

Finalmente, consideramos que FEAM debe replantearse, pues, de manera solapada está al servicio de la carrera comercial de algunas y algunos artistas. Es necesario que salga del circuito mercantil del arte contemporáneo y que se enfoque en la reconciliación de millones de víctimas de la guerra e invente espacios igualitarios, incluyentes y solidarios.

\section{Referencias}

Agamben, G. (2019). Creación y anarquía. La obra en la época de la religión capilatista. Buenos Aires: Adriana Hidalgo.

Arboleda Zárate, L. (2019). Los enredos del segundo monumento a la paz. El Espectador, 27 de abril. Disponible en: https://tinyurl.com/ydo699uh Consultado en noviembre de 2020 .

Arcadia. (2018). Así es la obra que Doris Salcedo está construyendo con las armas de las Farc. Arcadia. Disponible en: 
«https://tinyurl.com/e2sa2w2v», Consultado en noviembre de 2020.

Ávila Cortés, C. (2020). ¿Qué pasó con los monumentos hechos con las armas de las Farc?. El Espectador, 29 de junio. Disponible en: «https://tinyurl.com/37ax743y», Consultado en noviembre de 2020.

Carreño León, D. (2019). Fragmentos, más allá de su arte. El Espectador, 22 de enero. Disponible en: «https://tinyurl. com/3dksm76v», Consultado en noviembre de 2020.

Foucault, M. (2010). Los intelectuales y el poder. En Obras esenciales. Barcelona: Paidós.

González, J. (2019). Conflicto y creación. .Agenda Vogue.98. 30 de noviembre. Disponible en: «https://tinyurl. com/3hsfuy8n», Consultado en noviembre de 2020

Malagón Llano, S. (2019). Doris Salcedo convoca a defender los logros del Acuerdo de Paz. Arcadia, 30 de enero, Disponible en: «https://tinyurl.com/yicn4t3z», Consultado en noviembre de 2020.

Mejor hablemos. (2019). Entrevista al artista Mario Opazo, 8 de febrero, Bogotá: City TV Disponible en: «https://tinyurl. com/myfpynij», Consultado en noviembre de 2020.

Ministerio de Cultura. (2018). Artista Mario Opazo hará el monumento a la paz que se instalará en la sede de la ONU en Nueva York, anunció el presidente Santos, 27 de abril, Bogotá: MINCULTURA. Disponible en: «https://tinyurl. com/58r46dsu», Consultado en noviembre de 2020.

Oficina del Alto Comisionado para la Paz. (2016). Acuerdo final para la terminación del conflicto \& la construcción de una paz estable y duradera, 24 de noviembre. Bogotá. Disponible en: «https://tinyurl.com/xrcdnkmt», Consultado en noviembre de 2020.

Rodríguez, G.P. (2011). Los límites del perdón. Notas sobre la justicia transicional en Sudáfrica, Centroamérica y Colombia, en Justicia Juris, No. 2. Disponible en: «https://tinyurl.com/4p7stmm7», Consultado en noviembre de 2020. Resolución 2655. (2018). Diario Oficial de la República de Colombia. N.o 50.680. Bogotá D.C.

Sierra León, Y. (2017). “Reparación Simbólica, Litigio Estético y Litigio Artístico: Reflexiones en torno al arte, la cultura y la justicia restaurativa en Colombia", en Serie Documentos de Trabajo. Departamento de Derecho
Constitucional. Universidad Externado de Colombia. Disponible en: «https://tinyurl.com/3x2ui3u9», Consultado en noviembre de 2020.

Universidad Externado de Colombia. (2017). "29 recomendaciones del coloquio universitario "El monumento con las armas fundidas de las FARC-EP", 1 de noviembre. Disponible en: «https://tinyurl.com/ymxcd5ku», Consultado en noviembre de 2020.

Zizek, S. (2018). El coraje de la desesperanza. Crónicas del año en que actuamos peligrosamente. Barcelona: Anagrama. 